J. Lake Sci. (湖泊科学), 2022, 34(2): 601-615

DOI 10. $18307 / 2022.0220$

(c) 2022 by Journal of Lake Sciences

\title{
鄱阳湖环湖灌区枯季缺水量分析及对策建议”
}

\author{
李振旗 $^{1}$, 程和琴 ${ }^{* * *}$, 李纪人 ${ }^{2}$, 向诗月 ${ }^{1}$, 滕立志 ${ }^{1}$ \\ (1: 华东师范大学河口海岸学国家重点实验室, 上海 200241) \\ (2: 中国水利水电科学研究院, 北京 100038 )
}

\begin{abstract}
摘 要: 近年来, 在以三峡大坝为代表的一系列流域人类活动作用下, 鄱阳湖出现了枯水期延长、水位提前消落的现象, 导致了一系列生态环境和民生问题. 本文从环湖灌溉缺水入手,采用 11 种概率分布分析 1953-2018 年星子站水位,进行 比较优选后选择Wakeby 分布作为理论分布, 得到 $90 \%$ 保证率下的湖泊年平均水位及枯季 9 月至翌年 2 月月平均水位, 并 据历年平均水位选取代表水文年, 进行环湖灌区水资源供需分析, 获得缺水量. 在此基础上, 建立灌区缺水量变化与长江 干流流量变化的量化关系,讨论其应对策略. 结果表明: 自 2003 年三峡工程运行以来, 由于湖泊枯季水位降低, $90 \%$ 保证 率下鄱阳湖环湖灌区 9 月至翌年 2 月的缺水量已达到 2.26 亿、. 2.12 亿、0.57 亿、0.58 亿、0.55 亿、0.25 亿 m $^{3}$. 通过调节长 江干流流量满足环湖灌区用水需求的方案受到时段和“五河”来水状况的限制, 即该方案仅适用于枯季 9-10月 “五河” 来水减少的情况下. 受限于这些条件, 调节长江来水并非治本之策, 目前仍需采取其他更为有效的手段以恢复鄱阳湖的 水位及其过程.
\end{abstract}

关键词: 环湖灌区; 鄱阳湖;湖泊水位; 灌溉保证率;枯季缺水量

\section{Water shortage and countermeasures of irrigation area around Lake Poyang in dry sea- sons *}

Li Zhenqi ${ }^{1}$, Cheng Heqin ${ }^{1 * *}$, Li Jiren ${ }^{2}$, Xiang Shiyue ${ }^{1} \&$ Teng Lizhi ${ }^{1}$

(1: State Key Laboratory of Estuarine and Coastal Research, East China Normal University, Shanghai 200241, P.R.China)

(2: China Institute of Water Resources and Hydropower Research, Beijing 100038, P.R.China)

\begin{abstract}
In recent years, due to the influence of a series of human activities around the river basin represented by the Three Gorges Dam, the dry season duration of Lake Poyang was prolonged and early drawdown of water level was observed. This leads to a series of ecological and livelihood issues. To investigate the water shortage of irrigation around the lake, this paper analyzed the water level of Xingzi Station from 1953 to 2018 by applying eleven probability distribution functions. The Wakeby distribution was selected as the theoretical distribution after comparison. Both the mean annual water level and mean monthly water level during the dry season under a $90 \%$ guarantee rate were obtained. Based on the mean annual water level over the years, the representative hydrological year was selected to analyze the supply and demand of water resources, thus the water shortage was obtained. Consequently, the quantitative relationship between water shortage change of the irrigation area and water discharge change of the main channel of Changjiang River was established, and the countermeasures were discussed. The results show that the water shortage (under $90 \%$ guarantee rate) of irrigation area around Lake Poyang has accordingly reached 226 million m ${ }^{3}, 212$ million $\mathrm{m}^{3}, 57 \mathrm{million} \mathrm{m}^{3}, 58$ million $\mathrm{m}^{3}, 55$ million $\mathrm{m}^{3}$ and 25 million $\mathrm{m}^{3}$ from September to February of the next year, since the operation of the Three Gorges Dam in 2003. The solution to meet the water demand of the irrigation area by regulating the water discharge of the main channel of Changjiang River is only applicable to the situation when the water discharge from the 'Five Rivers' decreases in September and October. Therefore, to restore the water level of Lake Poyang and its process, other more effective means are needed.
\end{abstract}

Keywords: Irrigation area; Lake Poyang; lake level; irrigation guarantee rate; water shortage; dry season

* 2021-02-28 收稿; 2021-07-02 收修改稿.

国家自然科学基金委 (NSFC) 一荷兰科学研究组织 (NWO) 一英国研究理事会 (RCUK) 合作研究项目 (51761135023) 和中国地质调查局“长江经济带地质资源环境综合评价”项目 (DD20190260) 联合资助.

** 通信作者;E-mail: hqch@ sklec.ecnu.edu.cn. 
鄱阳湖位于江西省北部, 长江中下游南岸, 是我国最大的淡水湖泊, 在整个长江流域的水资源配置中占 有十分重要的地位, 并直接控制着鄱阳湖区的工农业生产和城乡居民生活用水. 鄱阳湖区是我国著名的鱼 米之乡, 也是我国重要的产粮基地之一. 根据本研究对象特点, 其范围是直接以鄱阳湖为灌溉水源的区域, 主要分布于南昌市、九江市和上饶市 ${ }^{[1]}$, 满足环湖农田灌溉需求是保障鄱阳湖区水资源安全、粮食安全的必 要条件.

鄱阳湖具有 “高水是湖, 低水似河, 洪水一片, 枯水一线” 的典型特征, 且降雨时空分布不均, 湖区水位变 幅大, 而环湖区农业灌溉设施落后, 灌溉取水能力很大程度上取决于湖区水位, 当湖区处于低水位时, 灌溉 取水量小于作物需水量, 因而存在枯季缺水的问题. 尤其是自 2003 年以来,在区域气候变化 ${ }^{[2]}$ 、土地覆盖变 化 ${ }^{[3]}$ 、长江干流河槽冲刷 ${ }^{[4-5]}$ 、三峡及长江上游控制性水库群兴利蓄水 ${ }^{[6-7]}$ 及湖盆形态变化 ${ }^{[8]}$ 的叠加作用下, 湖区枯季水位呈现显著下降的趋势 ${ }^{[9-10]}$, 枯水期延长、水位提前消落, 这直接导致鄱阳湖环湖灌区枯季缺水 日益严重,阻碍当地的经济和社会发展.

为应对当前鄱阳湖枯水形势下产生的一系列生态环境问题和包括灌溉在内的民生问题, 国内外专家学 者主要提出了以下几条对策: (1) 合理规划鄱阳湖流域及长江上游水库群蓄水运行方案, 增加汛后下泄水 量 ${ }^{[11]}$; (2) 严格鄱阳湖区人工采砂管理制度, 严禁非法采砂, 同时适当填砂进行湖床修复 ${ }^{[12]}$; (3) 严格鄱阳 湖区水资源管理制度,禁止超采、浪费 ${ }^{[13]} ;$; (4) 加强农业节水灌溉工程建设, 提升水源工程取水能力 ${ }^{[14]} ;(5)$ 在鄱阳湖人江水道长岭一屏峰山湖段兴建鄱阳湖水利枢纽工程以抬高枯水期湖泊水位, 减少湖口出流, 采取 “调枯不调洪” 的运行调度方案 ${ }^{[15]}$, 该方案不仅可以解决环湖灌区缺水问题, 而且可以实现生态保护、城乡 供水、改善湖区航运条件、枯水期为下游补水等多个目标. 然而, 目前国内外对于建设鄱阳湖水利枢纽工程 仍然存在较大争议, 如 Zhang 等 ${ }^{[16]}$ 认为修建鄱阳湖水利枢纽工程需要在更广泛的湖泊监测数据基础上进一 步考虑其长远影响; 周建军等 ${ }^{[17]}$ 研究指出建设鄱阳湖水利枢纽工程不仅严重影响鄱阳湖区的生态环境及生 物多样性, 而且会造成潮流界和潮区界上移, 影响下游及长江口供水安全.

因此, 本文选择鄱阳湖枯水导致的环湖灌溉缺水问题进行分析, 重新评估环湖灌区枯季缺水状况并探 究切实可行的解决措施. 评估灌区缺水状况最直接的指标就是灌区缺水量. 灌区缺水量分析的基本原则为 水量平衡原理, 即缺水量等于供需水量之差, 大体上可分为两类:其一是建立灌区水资源配置模型, 模型可 采用不同算法,如粟晓玲等 ${ }^{[18]}$ 采用人工鱼群算法和粒子群算法预测了陕西省渠井灌区枯水年的缺水量,陈 红光等 ${ }^{[19]}$ 构建区间两阶段鲁棒优化模型计算了黑龙江省牡丹江灌区不同来水流量下的缺水量, 万小庆 等 ${ }^{[20]}$ 基于现有水资源配置方案计算了鄱阳湖环湖灌区缺水量; 其二是根据灌区历史资料采用概率分布函数 拟合各种来水状况, 即可得到不同来水状况下的灌区缺水量, 如戴士岗 ${ }^{[21]}$ 采用 P-III 分布计算了江苏省南京 市六合区山湖一河王坝水库灌区的缺水量.

以往研究虽已提出了灌区缺水量的分析方法, 但鲜有针对鄱阳湖灌区的缺水量分析, 并且将缺水量与 应对措施联系起来进行探讨的研究较少. 本文采用水位保证率分析、代表水文年、M-K 趋势检验、K-S 检验、 多元线性回归等方法,推算环湖灌区缺水量,通过建立灌区缺水量变化与长江干流流量变化的量化关系初 步探讨其应对措施. 本研究弥补了以往对鄱阳湖环湖灌区枯季缺水状况量化研究的不足, 并引人了灌区缺 水量变化与长江干流流量变化的量化关系, 从定量的角度探讨了相应措施的可行性, 研究结果可为长江流 域水资源优化配置、相关水利枢纽工程优化调度运行方案等提供参考.

\section{1 研究区域概况}

鄱阳湖环湖灌区由取水受湖泊水位影响的农田组成, 多年平均降雨量为 $1542 \mathrm{~mm}$, 多年平均蒸发量为 $800 \sim 1100 \mathrm{~mm}$, 属于江西省降雨低值区和蒸发高值区, 年平均风速为 $2 \sim 3 \mathrm{~m} / \mathrm{s}$, 年平均气温为 $17.6^{\circ} \mathrm{C}$, 年均日 照时数达 $2000 \mathrm{~h}$ 以上, 无霜期达 $275 \mathrm{~d}$, 土壤质地松软, 有机质含量丰富, 农田灌溉水利用系数为 $0.45 \sim$ $0.50^{[1,22]}$. 环湖灌区有效灌溉面积 20.61 万 $\mathrm{hm}^{2}$, 其中包括水田 16.56 万 $\mathrm{hm}^{2}$, 水浇地 4.05 万 $\mathrm{hm}^{2}$, 主要分布于 滨湖平原及“五河”尾问 (图 1). “五河”尾问范围为“五河”七口控制性水文站(赣江外洲站、抗河李家渡站、 信江梅港站、饶河虎山站、修水虬津站、潦河万家埠站、昌江渡峰坑站, 图 1) 以下至湖盆区, 该区域灌区取水 受到湖泊水位影响的程度小于滨湖平原区. 对于不同季节, 灌区的主要灌溉对象也不同, 春季主要灌溉早稻 
和棉花, 夏季主要灌溉花生、芝麻等油料作物, 秋季主要灌溉晚稻和油菜, 冬季由于气温低, 大部分作物不适 宜生长, 需水较少, 但仍有一些豆类及蔬菜大棚需要灌溉. 近年来鄱阳湖湖区枯季水位持续偏低, 已导致灌 区发生多次秋冬连旱,影响作物产量.

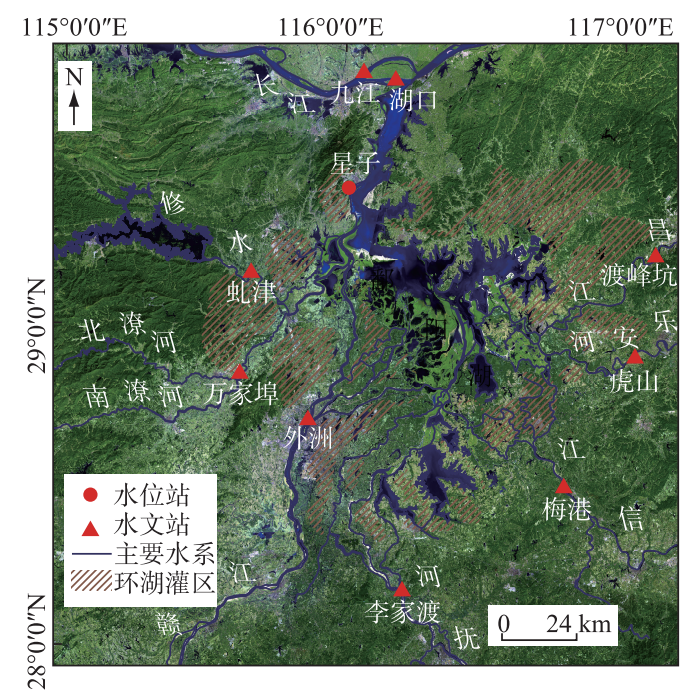

图 1 鄱阳湖水系及环湖灌区分布

(数据来源于中国科学院计算机网络信息中心地理空间数据云平台 http://www.gscloud.cn)

Fig.1 Lake Poyang system and the distribution of irrigation areas around the lake

(The data set is provided by Geospatial Data Cloud site, Computer Network Information Center,

Chinese Academy of Sciences. http://www.gscloud.cn)

\section{2 数据和方法}

\section{1 数据来源}

1953-2018 年星子水位数据采自江西省水文局星子站实测黄海基面月平均水位资料,将其转换为吴淞 基准面 (下文中除特殊说明外,水位统一采用此基准面); 湖泊容积选用基于 2010 年鄱阳湖基础地理测量成 果汇编的星子站 4 21 m 水位对应的数据 ${ }^{[24]}$ (1985 国家高程基准面), 并将其转换为吴淞基准面水位对应的 湖泊容积, 用于回归分析获得各水位对应的湖泊容积; 2003-2018 年湖口站、汉口站月均径流量资料由长江 泥沙公报的月径流总量换算获得,用于湖口站及汉口站流量调节分析.

\section{2 研究方法}

本文从湖泊水位人手, 采用多种概率分布拟合水位时间序列推求其理论分布, 进行水位保证率分析, 得 到不同保证率下的水位, 在此基础上分析灌区缺水量并建立缺水量变化与长江干流流量变化关系, 量化相 应措施的可行性. 具体步骤为: (1)利用水位保证率分析结果, 采用代表水文年法推算灌区需水量, 根据水位一 供水能力关系确定灌区可供水量, 得到灌区缺水量; (2)在满足灌区灌溉用水需求的情况下 (即某一保证率标 准下缺水量为 0 , 供水量等于需水量), 利用水位一湖泊容积关系得到湖泊蓄水量; (3)湖泊蓄水量变化由 “五 河” 入流和湖口出流引起, 采用 M-K 趋势检验分析二者变化趋势, 按最不利原则考虑, 可由水量平衡原理得 到湖口出流变化; (4)采用多元线性回归建立“五河” 来流和长江来水共同影响下的湖口出流变化关系,得到 不同“五河”来流情景下长江干流流量变化.

2.2.1 水位保证率分析 由于三峡工程的建设改变了长江流域的天然水文过程及江湖关系 ${ }^{[25]}$, 因此以三峡 工程 2003 年一期蓄水为时间节点, 对三峡建设前系列 (1953-2002 年) 及全系列 (1953-2018 年) 星子水 位数据分别进行统计分析, 以确定三峡工程对湖泊枯季水位的影响. 本文参照闵骞等 ${ }^{[26]}$ 依据湖泊水位提出 
的鄱阳湖枯水划分标准对鄱阳湖水文节律进行划分, 同时考虑到近年来鄱阳湖枯水期提前, 旱情主要发生 在 9 月至翌年 2 月,故将本次枯季计算时段定为 9 月至翌年 2 月.

由于 1953-2002 年和 1953-2018 年星子站年均水位序列和枯季 9 月至翌年 2 月月均水位序列服从的 总体概率分布未知, 本研究选取 Wakeby、对数正态、Gamma、Gumbel、广义极值 (GEV)、Weibull、P-III、对数逻 辑、广义 Pareto、广义逻辑、对数 P-III 分布 11 种概率分布作为备选线型, 分别对星子水位数据进行拟合. 采用 线性矩法估计各概率分布线型的参数, 再利用假设检验中的 K-S 检验统计量进行拟合优度评价, 选出拟合 最优线型 ${ }^{[27]}$, 将该线型的拟合结果作为本研究的水位保证率分析结果. 拟合结果中的概率百分数即为本研 究中的水位保证率 $p \%$, 其意义是大于或等于某一水位的情况在长时期内平均 100 年可能发生 $p$ 次 ${ }^{[28]}$, 因此 保证率越高水位越低. 各拟合线型的概率密度函数或概率分布函数表达式见附表 I .

2.2.2 缺水量分析 环湖灌区缺水量分析包括供水量分析和需水量分析. 具体过程如下:

需水量分析可选用代表水文年法 ${ }^{[28]}$, 对于给定的保证率 $p$, 其相应的年平均水位为 $H_{p}$, 在年均水位时 间序列 $\left\{H_{1}, H_{2}, H_{3}, \cdots, H_{n}\right\}$ 中选择与 $H_{p}$ 最相近的年份作为代表水文年, 以该年份的灌溉定额作为需水量 计算的基准,则有:

$$
W D_{p}=W D_{r} \frac{S_{y}}{S_{r}}
$$

式中, $W D_{p}$ 为保证率 $p$ 下的灌区年需水量 $\left(\mathrm{m}^{3}\right), W D_{r}$ 为代表水文年的灌区年需水量 $\left(\mathrm{m}^{3}\right), S_{y}$ 为灌区现状有 效灌溉面积 $\left(\mathrm{hm}^{2}\right), S_{r}$ 为代表水文年灌区有效灌溉面积 $\left(\mathrm{hm}^{2}\right)$.

保证率 $p$ 下的灌区枯季各月需水量可根据多年平均灌溉水量年内分配情况 (图 2) ${ }^{[23]}$ 按式 (2) 推算:

$$
W D_{p m}=W D_{p} \cdot R
$$

式中, $W D_{p m}$ 为保证率 $p$ 下的灌区枯季各月需水量 $\left(\mathrm{m}^{3}\right), R$ 为各月灌溉水量占年灌溉水量的比例.

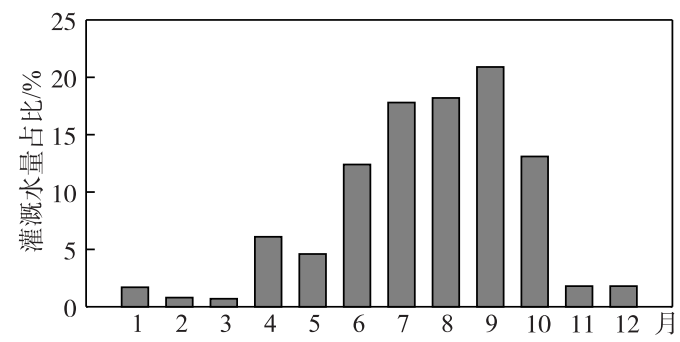

图 2 环湖灌区多年平均灌溉水量年内分配 ${ }^{[23]}$

Fig.2 The inner year distribution of mean annual irrigation quantity in irrigation area around Lake Poyang ${ }^{[23]}$

相同水位下,供水量与灌区灌溉设施供水能力息息相关. 对比近年来发表的相关文献 ${ }^{[23,29-30]}$ 中环湖灌 溉取水设施的底板高程或最低取水位数据, 环湖灌溉设施供水能力并无显著变化. 因此, 供水量分析可在上 文水位保证率分析的基础上采用徐卫红等 ${ }^{[31]}$ 通过实地调研得出的星子站水位与环湖灌溉设施供水能力关 系数据, 则有:

$$
W S_{p m}=f_{1}\left(H_{p m}\right)=\left\{\begin{array}{c}
10275 H_{p m}-82221(9 \text { 月 }) \\
6538.5 H_{p m}-52322(10 \text { 月 }) \\
186.96 H_{p m}-1496.6(11-12 \text { 月 }) \\
140.07 H_{p m}-1120.9(1-2 \text { 月 })
\end{array}\right.
$$

式中, $W S_{p m}$ 为保证率 $p$ 下的灌区枯季各月供水量 $\left(\right.$ 万 $\left.\mathrm{m}^{3}\right), f_{1}$ 为供水能力与星子站水位函数关系, $H_{p m}$ 为保 证率 $p$ 下的枯季各月月均水位 $(\mathrm{m})$.

缺水量为供需水量之差:

$$
L W_{p m}= \begin{cases}0 & \left(W D_{p m}-W S_{p m}<0\right) \\ W D_{p m}-W S_{p m} & \left(W D_{p m}-W S_{p m} \geqslant 0\right)\end{cases}
$$


式中, $L W_{p m}$ 为保证率 $p$ 下的枯季各月缺水量 $\left(\mathrm{m}^{3}\right)$.

2.2.3 Mann-Kendall 方法 Mann-Kendall( M-K) 趋势检验法是用于检测时间序列中显著性趋势的非参数检验 方法之一, 目前已广泛用于水文数据的趋势性检验 ${ }^{[32]}$. Mann-Kendall 趋势检验不受数据实际分布的影响, 与 参数检验方法相比不受异常值的干扰, 具有适用范围广、人为性少和定量化程度高的优点.

2.2.4 对策研究 参考相关文献中的星子站水位一湖泊容积数据 ${ }^{[24]}$, 对星子站水位一湖泊容积进行回归分 析, 得到拟合公式, 再根据水量平衡原理定量分析水资源供需平衡时长江干流流量. 具体步骤如下:

利用水位一湖泊容积数据得到拟合公式 $(5)$ :

$$
V_{p m}=f_{2}\left(H_{p m}\right)
$$

式中, $V_{p m}$ 为保证率为 $p$ 的水位对应的湖泊容积 $\left(\mathrm{m}^{3}\right), f_{2}$ 为水位一湖泊容积函数关系. 定义湖泊调蓄水量为 环湖灌区水资源供需达到临界平衡时需要从外界补足的水量, 若某一保证率标准下的湖泊容积大于临界平 衡时的湖泊容积, 则无需从外界补足水量, 湖泊调蓄水量为 0 ; 反之则为湖泊容积之差, 可按式 (6)、(7) 求得：

$$
\begin{gathered}
V_{s m}=f_{2}\left(f_{1}^{-1}\left(W D_{p m}\right)\right) \\
V_{w}= \begin{cases}0 & \left(V_{s m}-V_{p m}<0\right) \\
V_{s m}-V_{p m} & \left(V_{s m}-V_{p m} \geqslant 0\right)\end{cases}
\end{gathered}
$$

式中, $V_{s m}$ 为灌区水资源供需平衡时对应的湖泊容积 $\left(\mathrm{m}^{3}\right), V_{w}$ 为湖泊调蓄水量 $\left(\mathrm{m}^{3}\right)$.

根据水量平衡原理,得到式 (8)、(9):

$$
\begin{gathered}
V_{w}=-\left(\Delta Q_{\text {湖口 }}-\Delta Q_{\text {五河 }}\right) t \\
Q_{\text {湖口 }}^{\prime}=Q_{\text {湖口 }}+\Delta Q_{\text {湖口 }}
\end{gathered}
$$

式中, $\Delta Q_{\text {五河 }}$ 为 “五河” 入湖月均流量变化量 $\left(\mathrm{m}^{3} / \mathrm{s}\right), \Delta Q_{\text {湖口 }}$ 为湖口月均流量变化量 $\left(\mathrm{m}^{3} / \mathrm{s}\right), Q_{\text {湖口 }}^{\prime}$ 为调节后 湖口月均径流 $\left(\mathrm{m}^{3} / \mathrm{s}\right), Q_{\text {湖口 }}$ 为湖口站月均径流量 $\left(\mathrm{m}^{3} / \mathrm{s}\right), t$ 为时间 $(\mathrm{s})$.

长江干流水文站中九汇站最接近鄱阳湖口, 但考虑到近年来在海平面上升作用下 ${ }^{[33]}$ 枯季长江潮区界已 上移至九江附近 ${ }^{[34]}$, 九江站流量已不能准确反映长江干流水情. 汉口站位于武汉市附近, 汉江与长江干流 交汇口处, 能够较好地反映长江干流水文情势, 故以汉口站流量代表长江干流流量, 对调节长江干流流量以 减少湖口出流进行定量分析. 由于湖口出流量取决于长江和鄱阳湖相互作用的相对强弱程度, 可直接以流 量变化量表征,则有式(10)、(11):

$$
\begin{gathered}
\Delta Q_{\text {湖口 }}=f_{3}\left(\Delta Q_{\text {汉口 }}, \Delta Q_{\text {五河 }}\right) \\
Q_{\text {汉口 }}^{\prime}=Q_{\text {汉口 }}+\Delta Q_{\text {汉口 }}
\end{gathered}
$$

式中, $\Delta Q_{\text {汉口 }}$ 为汉口站流量变化量 $\left(\mathrm{m}^{3} / \mathrm{s}\right), f_{3}$ 为函数关系, $Q_{\text {汉口 }}^{\prime}$ 为调节后汉口站月均径流量 $\left(\mathrm{m}^{3} / \mathrm{s}\right)$.

\section{3 结果和讨论}

\section{1 水位保证率分析结果}

选取 Wakeby、对数正态、Gamma 等 11 种概率分布对星子水位系列进行拟合, 并采用 K-S 检验评价拟合 优度,得到各分布线型的参数估计结果 (附表 II 、附表 III) 和 K-S 检验结果 (表 1). 将 K-S 检验统计量按照大 小顺序排列, 最小值对应的概率分布拟合最优, 最大值对应的概率分布拟合最差. 总体而言, 拟合数据系列 较好的概率分布为 Wakeby 分布和广义极值分布. 对于年均水位序列, Wakeby 分布拟合更优; 对于月均水位 序列, 9、10 和 1 月 Wakeby 分布拟合更优, 11 、12 和 2 月广义极值分布拟合更优. 但是,在 $11 、 12$ 和 2 月月均 水位序列中, 比较 Wakeby 分布和广义极值分布 K-S 检验统计量的差值均小于 0.01 , 为保持数据系列拟合概 率分布的一致性, 可认为月均水位序列整体服从 Wakeby 分布. 因此, 选择 Wakeby 分布作为拟合最优理论分 布进行水位保证率计算, 得到不同保证率下的年均水位和枯季月均水位. 显著性水平为 $0.05,1953-2002$ 年 水位系列临界值为 $0.1884,1953-2018$ 年水位系列临界值为 0.1644 .

根据参数估计结果计算得到各系列的风险函数 (Survival Function), 绘于海森概率格纸上, 即为 $1953-$ 2002 和 1953-2018 年两个系列不同保证率下的星子年均水位 (图 3) 和枯季月均水位 (图 4). 相比 19532002 年, 1953-2018 年水位一保证率关系曲线均出现了不同程度的下移, 各个保证率对应的水位总体而言 
表现出下降的趋势, $90 \%$ 保证率下的年均水位和枯季 9 月至翌年 2 月月均水位分别下降了 $0.35 、 0.69 、 0.86$ 、 $0.55 、 0.14 、 0 、 0.09 \mathrm{~m}$, 降幅分别为 $2.8 \% 、 5.2 \% 、 7.0 \% 、 5.4 \% 、 1.7 \% 、 0 \% 、 1.2 \%$. 由此可见, 将三峡运行后时期纳 人分析范围后, 湖区枯季 9-11 月水位显著下降, 这可能是受到三峡及其上游控制性水库群汛末大量蓄水 及人工采砂导致的湖盆形态变化 ${ }^{[35-36]}$ 的影响. 其他月份虽然下降不显著, 但仅增加 2003-2018 年 16 年数 据相对于整体分布而言样本数较少, 其实际变化幅度必然大于该结果, 如游中琼等 ${ }^{[37]}$ 直接比较了 $1956-$ 2002 年与 2003-2018 年鄱阳湖湖区各站枯水期水位差, 发现鄱阳湖枯水期水位显著降低.

表 1 各概率分布的 K-S 检验结果 ${ }^{1)}$

Tab.1 K-S test results for each probability distribution

\begin{tabular}{|c|c|c|c|c|c|c|c|c|}
\hline 系列 & 分布 & 年均 & 9 月 & 10 月 & 11 月 & 12 月 & 1 月 & 2 月 \\
\hline \multirow[t]{12}{*}{$1953-2002$ 年 } & Wakeby & $0.0797^{*}$ & $0.0840^{*}$ & 0.0835 & 0.0438 & 0.0581 & $0.0527^{*}$ & 0.0785 \\
\hline & 对数正态 & 0.0869 & 0.1315 & 0.1010 & 0.0550 & 0.0807 & 0.0783 & 0.0825 \\
\hline & Gamma & 0.0921 & 0.1244 & 0.0999 & 0.0482 & 0.0892 & 0.0951 & 0.0751 \\
\hline & Gumbel ( min) & 0.1690 & 0.1258 & 0.1212 & 0.1251 & 0.1763 & 0.1479 & 0.1542 \\
\hline & Gumbel(max) & 0.1186 & 0.1789 & 0.1392 & 0.0929 & 0.0614 & 0.0618 & 0.1178 \\
\hline & 广义极值 & 0.0933 & 0.1099 & 0.0781 & $0.0434^{*}$ & $0.0571 *$ & 0.0662 & $0.0750 *$ \\
\hline & Weibull & 0.1243 & 0.1019 & 0.0829 & 0.0773 & 0.1262 & 0.0839 & 0.1027 \\
\hline & P-III & 0.3400 & 0.3600 & 0.3733 & 0.3800 & 0.3333 & 0.3533 & 0.3933 \\
\hline & 对数逻辑 & 0.0869 & 0.1503 & 0.1177 & 0.0777 & 0.0623 & 0.0678 & 0.1108 \\
\hline & 广义 Pareto & 0.1200 & 0.1543 & 0.0928 & 0.0760 & 0.0859 & 0.0820 & 0.0984 \\
\hline & 广义逻辑 & 0.0820 & 0.1036 & 0.1020 & 0.0615 & 0.0619 & 0.0746 & 0.0867 \\
\hline & 对数 P-III & 0.0959 & 0.1042 & $0.0772 *$ & 0.0500 & 0.0658 & 0.0663 & 0.0800 \\
\hline \multirow[t]{12}{*}{$1953-2018$ 年 } & Wakeby & 0.0660 * & $0.0581 *$ & $0.0582 *$ & 0.0408 & 0.0584 & $0.0570 *$ & 0.0648 \\
\hline & 对数正态 & 0.0783 & 0.1257 & 0.0885 & 0.0487 & 0.0907 & 0.0933 & 0.0766 \\
\hline & Gamma & 0.0750 & 0.1205 & 0.0768 & $0.0398^{*}$ & 0.1003 & 0.0881 & 0.0727 \\
\hline & Gumbel ( min) & 0.1224 & 0.0954 & 0.1024 & 0.1277 & 0.1845 & 0.1553 & 0.1544 \\
\hline & Gumbel( max) & 0.1284 & 0.1709 & 0.0992 & 0.0850 & 0.0568 & 0.0807 & 0.0995 \\
\hline & 广义极值 & 0.0747 & 0.1038 & 0.0699 & 0.0446 & 0.0602 & 0.0788 & 0.0664 \\
\hline & Weibull & 0.0866 & 0.0869 & 0.0703 & 0.0792 & 0.1398 & 0.1024 & 0.1057 \\
\hline & P-III & 0.3576 & 0.3545 & 0.3727 & 0.3545 & 0.3242 & 0.3273 & 0.3848 \\
\hline & 对数逻辑 & 0.0897 & 0.1417 & 0.0935 & 0.0607 & 0.0715 & 0.0957 & 0.0951 \\
\hline & 广义 Pareto & 0.1046 & 0.1548 & 0.1162 & 0.0766 & 0.0900 & 0.0786 & 0.0647 * \\
\hline & 广义逻辑 & 0.0897 & 0.0898 & 0.0762 & 0.0495 & $0.0555^{*}$ & 0.0939 & 0.0863 \\
\hline & 对数 P-III & 0.0800 & 0.0922 & 0.0681 & 0.0431 & 0.0693 & 0.0773 & 0.0754 \\
\hline
\end{tabular}

1) 表中数据为 K-S 检验统计量, 标“ *”数据为最小值.

\section{2 环湖灌区枯季缺水量}

显然,2003 年后鄱阳湖的水文情势发生了急剧变化,分析环湖灌区缺水现状需考虑 2003 年三峡运行后 对湖区水位的影响,故本文以 1953-2018 年水位分析结果为基础,计算环湖灌区缺水量.

环湖灌溉缺水的本质在于湖区水位过低致使灌溉工程设施无法按需取水,而水位保证率系指长时期内 水位大于等于某个值的概率, 那么在某一水位保证率下, 使得环湖灌溉水量达到供需平衡临界时, 只要水位 大于该保证率对应的水位特征值就能保障灌区用水. 因此,上文分析得到的水位保证率即为灌溉设计保证 率. 按照《灌溉与排水工程设计标准》 (GB 50288-2018) ${ }^{[38]}$, 鄱阳湖环湖灌区位于湿润地区, 同时存在地面 灌溉和喷微灌等不同灌溉方式, 作物种类多样, 其灌溉设计保证率应为 85\% 95\%, 故本文以 90\% 保证率作 为设计标准. 将 90\% 保证率下的星子站年均水位与 2003-2018 年星子站实测年均水位进行对比(图 5), 确 定 2018 年为代表水文年, 以该年的灌溉定额作为需水量计算依据,则按式 (1)、(2)计算得到的环湖灌区枯 季 9 月至翌年 2 月的需水量分别为 6.94 亿、 4.35 亿、 0.6 亿、0.6亿、0.56亿、0.27 亿 $\mathrm{m}^{3}$. 根据环湖灌区农业灌 


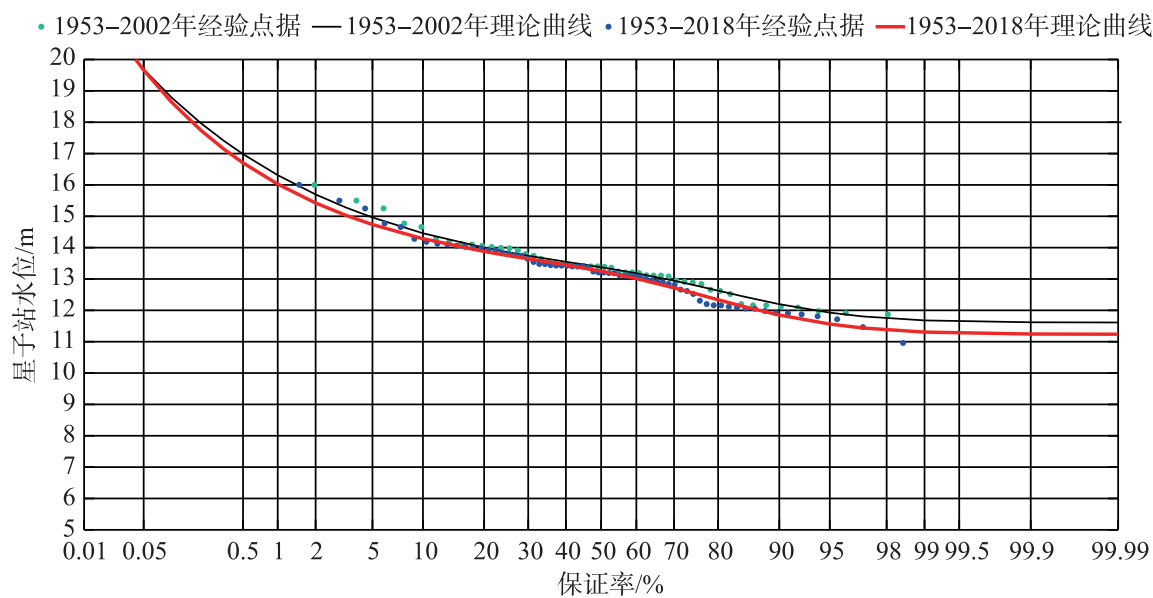

图 3 星子站年均水位拟合效果

Fig.3 Curve fitting of mean annual water level at Xingzi Station

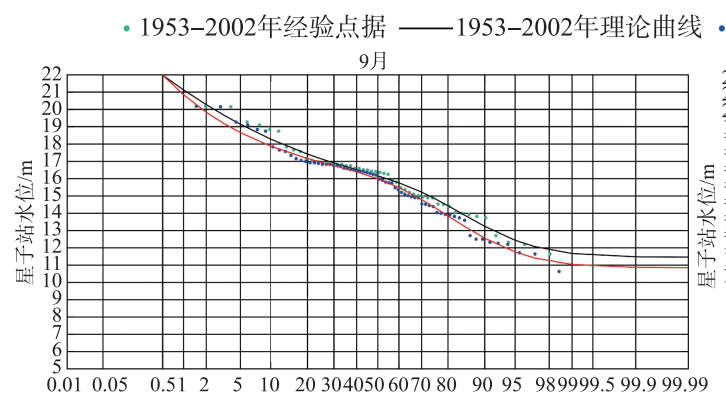

保证率/\%

11月

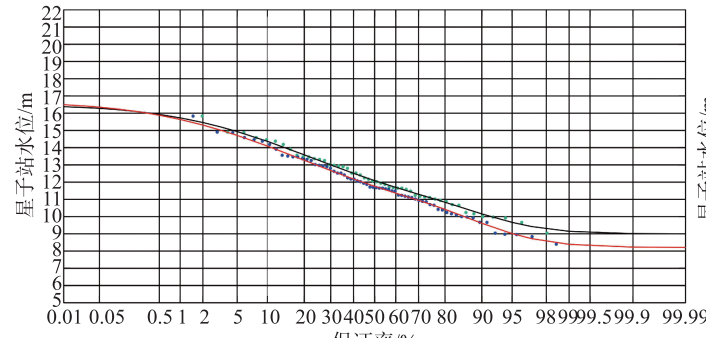

保证率/\%

1 月

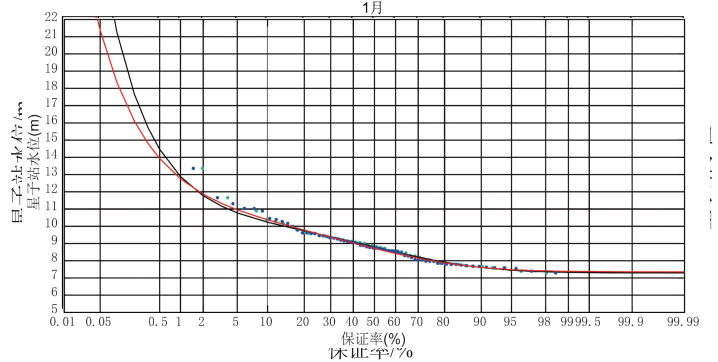

图 4 星子站枯季月均水位拟合效果

Fig.4 Curve fitting of mean monthly water level at Xingzi Station in dry season
-1953-2018年理论曲线

10月

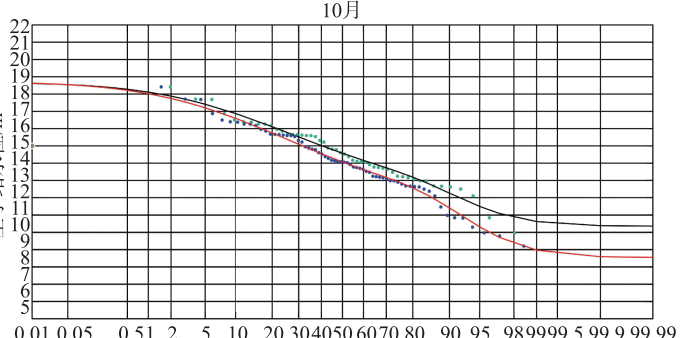

保证率 $/ \%$

12月

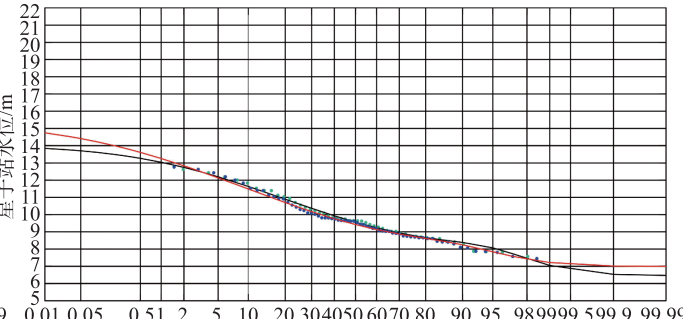

保证率 $\%$

2月

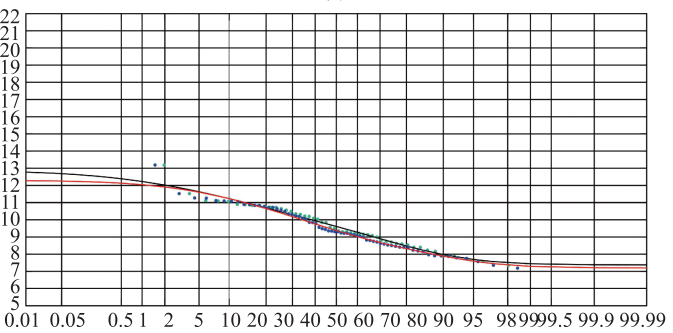

保证率/\% 


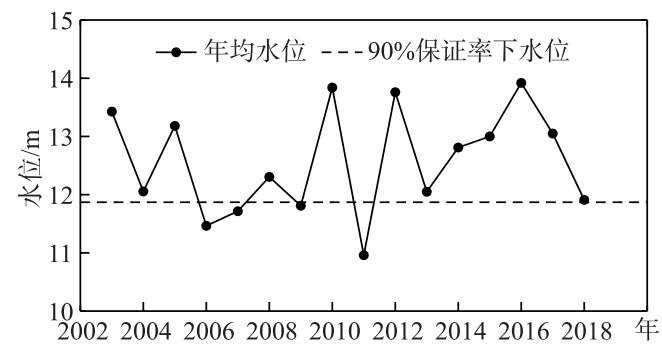

图 $52003-2018$ 年星子站年均水位

Fig.5 Mean annual water level at Xingzi Station from 2003 to 2018
溉设施供水能力与星子站水位关系, 将 $90 \%$ 保证率下 的枯季各月水位转换为可供水量, 按公式 (3) 计算, 得 到枯季 9 月至翌年 2 月的供水量分别为 4.68 亿、 2.23 亿、0.03 亿、0.02 亿、0.01 亿、0.01 亿 $\mathrm{m}^{3}$, 则缺水量分别 为 2.26 亿、 2.12 亿、 0.57 亿、 0.58 亿、 0.55 亿、 0.25 亿 $\mathrm{m}^{3}$.

\section{3 鄱阳湖流域枯季出入湖径流变化}

环湖灌区缺水是湖区水位过低所致, 故在枯季抬 高湖区水位即可满足需求. 然而, 湖区水位受到“五 河”来流和湖口出流的双重影响, 因此有必要对近年来 鄱阳湖流域枯季出人湖径流变化进行探讨. 鄱阳湖为 一吞吐型湖泊,其湖盆汇集“五河”流域来水和区间来

水后由湖口注人长江. 鄱阳湖流域枯季出入湖径流变化特征 (图 6) 包括人湖径流变化和出湖径流变化. 人 湖径流为 “五河” 七口人湖控制站及未控区间来流之和, 出湖径流为湖口站径流量, 其中未控区间来流可采 用面积比拟法, 即以“五河” 七口站同期流量为参照,按集水面积之比推算, 面积比可取 $0.19^{[39]}$. 考虑到 “五 河” 流域和滨湖未控区间的下垫面条件不同,具体计算时还需要比较二者间径流系数的差异,在面积比的基 础上乘以径流系数比. 参考相关研究 ${ }^{[40-41]}$, “五河” 流域多年平均径流系数为 0.568 , 未控区间多年平均径流 系数为 0.4 ,则径流系数比为 0.7 .
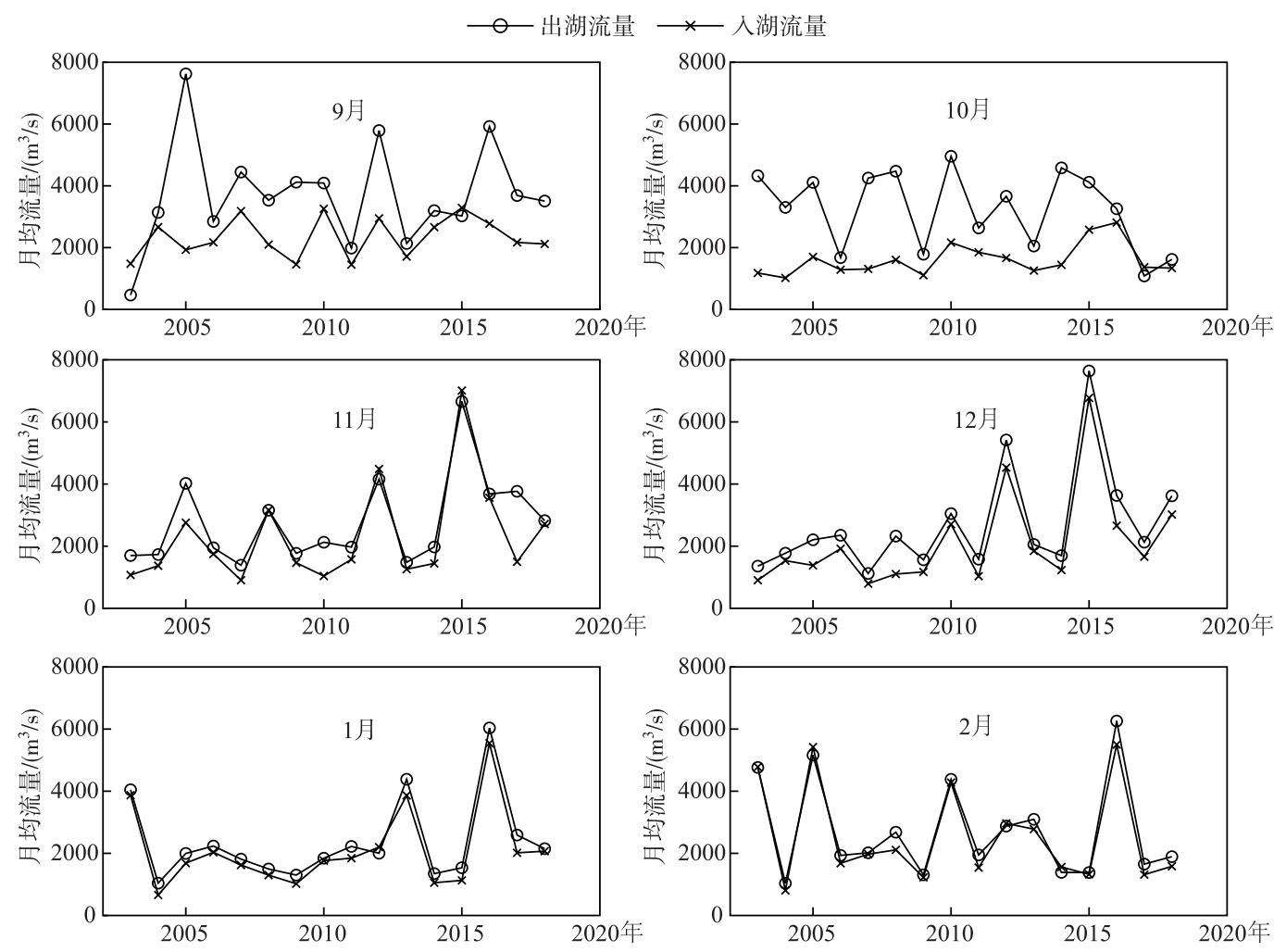

图 6 鄱阳湖流域枯季出入湖径流变化特征

Fig. 6 Variation of runoff in and out of Lake Poyang Basin in dry season 总体而言, 2003-2018 年枯季各月人湖径流量小于湖口出湖径流量, 这表明鄱阳湖枯季水资源量处于 
流失状态, 其中 9-10月份水资源外流最为严重, 出湖流量与人湖流量差 9 月份最大达到 $5695 \mathrm{~m}^{3} / \mathrm{s}, 10$ 月 份最大达到 $3147 \mathrm{~m}^{3} / \mathrm{s}$. 此外, 枯季 11 月至翌年 2 月的出湖流量变化过程与人湖流量变化过程相近, 而 $9-$ 10 月二者具有较大差异, 这可能是由于 9-10 月长江水位较高, 长江对鄱阳湖出流的影响在 9-10 月更加 显著.

采用 Mann-Kendall 法分析枯季人湖径流和出湖径流的变化趋势 (图 7), 显著性水平 $\alpha$ 取 0.05. 9-12 月 人湖径流均呈现上升趋势, 1 月人湖径流在 2003-2011 年呈现下降趋势, 在 2012-2018 年呈现上升趋势, 2 月人湖径流呈现波动稳定的状态. 9 月、 11 月和 12 月出湖径流均呈现上升趋势, 10 月和 2 月出湖径流呈现 波动稳定的状态, 1 月出湖径流在 2003-2012 年呈现下降趋势, 在 2013-2018 年呈现上升趋势, 与人湖径 流变化趋势相似. 总体而言,鄱阳湖流域枯季人湖径流与出湖径流均呈现上升趋势.
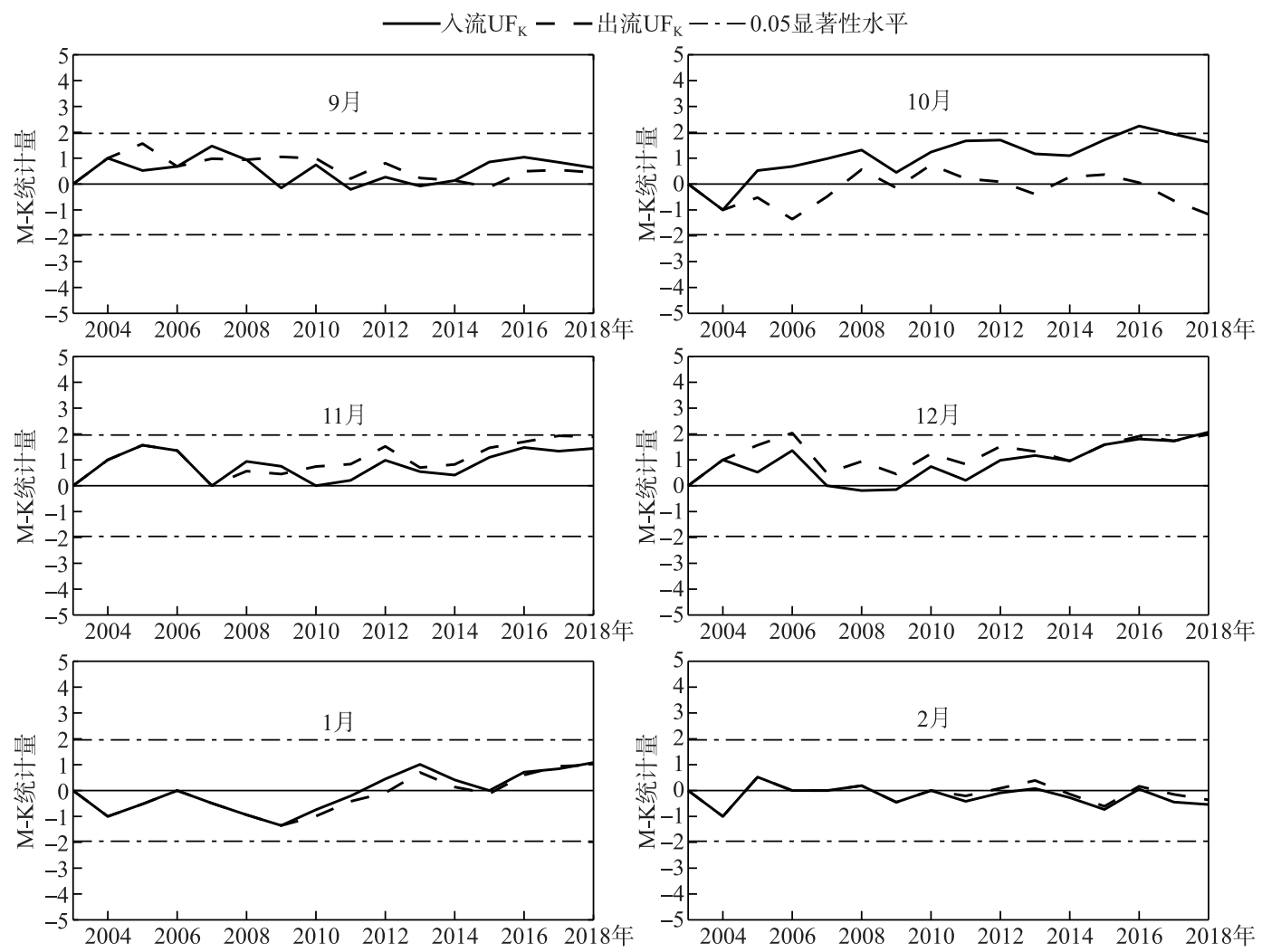

图 7 鄱阳湖流域枯季出人湖径流趋势分析

Fig.7 Trend analysis of runoff in and out of Lake Poyang Basin in dry season

\section{4 对策研究}

由于鄱阳湖流域枯季人湖径流与出湖径流均呈现上升趋势, 假定水下地形条件不变, 人湖径流的增加 有助于湖泊水位的上涨, 而湖口出湖径流的增加则不利于湖泊水量的蓄存, 针对本文所研究的问题, 只考虑 不利于环湖灌区用水的要素, 可认为增加的湖泊调蓄水量全部由湖口补给, 以满足环湖灌区用水需求, 则式 (8) 变为:

$$
V_{w}=-\Delta Q_{\text {湖口 }} \cdot t
$$

3.4.1 水位一湖泊容积关系 根据 2010 年鄱阳湖基础地理测量成果汇编的星子站 4 21 m 水位对应的数 据 ${ }^{[24]}$ (1985 国家高程基准面)，经过基面转换及多项式拟合得到吴淞基准面下水位一湖泊容积关系(图 8). 鉴于鄱阳湖复杂的地形特征及其与长江间特殊的江湖关系, 水位一湖容曲线在 $9-10$ 月和 $11-2$ 月间表现 出不同的特性. 当湖区水位较高时 (星子站水位 $\geqslant 15 \mathrm{~m}$ ), 两个时段对应的水位一湖容关系相近, 湖区水位较 


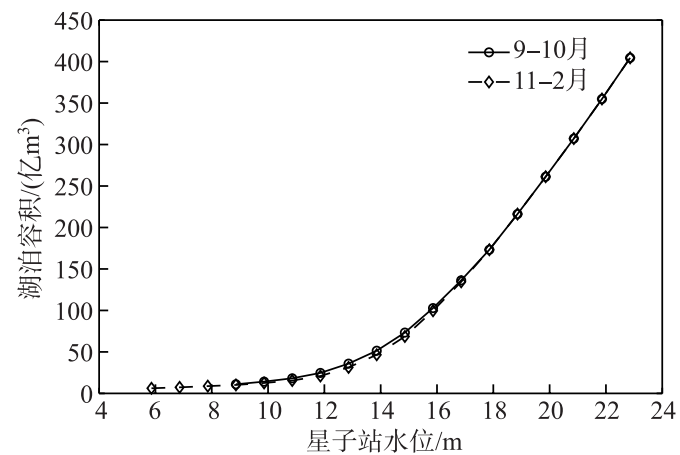

图 8 星子站水位与鄱阳湖容积关系 (数据取自文献 $[24]$ )

Fig. 8 The relationship between water level at Xingzi Station and Lake Poyang storage (Data from the literature[24])

低时 (星子站水位 $<15 \mathrm{~m}$ ), 两个时段对应的水位一 湖容关系有所差异, 其原因在于, 相比 11-2 月,910 月长江水位较高, 鄱阳湖湖区受到长江来水顶托 的影响较大, 湖区将容留更多水量, 故同水位时 910 月对应的湖泊容积往往大于 $11-2$ 月,且低水位 时这种差异更加显著. 可见, 水位一湖泊容积关系曲 线从某种程度上也反映了翻阳湖与长江间的相互作 用状态. 因此, 本文按照 9-10月、11-2 月两个计算 时段拟合的不同公式估算 $90 \%$ 保证率下枯季各月水 位相应的湖泊容积.

3.4.2 湖泊调蓄水量 根据 $90 \%$ 保证率下的枯季 9 月 至翌年 2 月水位结果 (图 4)、拟合的水位一湖泊容积 函数关系(表 2) 及公式 (6) (7) 计算获得 90\% 保证 率下的枯季 9 月至翌年 2 月湖泊调蓄水量分别为 42.09 亿、53.27 亿、41.53 亿、41.85 亿、41.88 亿、41.82 亿 $\mathrm{m}^{3}$. 枯季各月中, 除 10 月湖泊调蓄水量偏大外, 其 他月份湖泊调蓄水量相近.

3.4.3 流量调节分析 依据长江干流与鄱阳湖相互作用的相对强弱, 湖口站径流量分别受到长江干流来水的 倒灌、顶托和拉空影响, 因此可通过调节长江干流流量来达到减少湖口出流的目的. 为定量分析满足环湖灌 区需水时的长江下泄流量, 以“五河” 入湖流量变化量表征鄱阳湖作用强度 ${ }^{[42]}$, 以汉口站流量变化量表征长 江作用强度 ${ }^{[43]}$, 建立多元线性回归模型 ${ }^{[4]}$ 分析二者综合作用下的湖口出流规律, 并采用 2003-2018 年枯 季“五河” 人湖流量、汉口流量和湖口流量数据率定模型参数, 得到枯季 $9-10$ 月、11 月至翌年 2 月两个不同 时段的湖口出流量变化与 “五河” 来水变化、长江来水变化关系 (表 3 ), 复相关系数均在 0.9 以上, 且都通过 了 0.05 水平的 $F$ 显著性检验, 为显著相关.

表 2 不同时段水位一鄱阳湖容积关系公式*

Tab.2 The regression formula of water level at Xingzi Station and Lake Poyang storage during different periods

\begin{tabular}{ccc}
\hline 计算时段 & 拟合公式 & 相关系数 $R^{2}$ \\
\hline $9-10$ 月 & $V=2.1685 H^{2}-40.076 H+195.36$ & 0.9991 \\
$11-2$ 月 & $V=-0.0123 H^{4}+0.7219 H^{3}-12.957 H^{2}+93.908 H-231.13$ & 0.9999 \\
\hline
\end{tabular}

$* V$ 为鄱阳湖容积 $\left(\right.$ 亿 $\left.\mathrm{m}^{3}\right), H$ 为星子站水位 $(\mathrm{m})$.

表 3 “五河”来水及长江来水变化下的枯季湖口出流变化

Tab.3 Variation of outflow at Hukou Station in dry season dominated by the change of runoff of the 'Five Rivers' and Changjiang River

\begin{tabular}{ccccc}
\hline \multirow{2}{*}{ 计算时段 } & 拟合关系 & $\begin{array}{c}\text { 复相关 } \\
\text { 系数 } R\end{array}$ & $\begin{array}{c}\text { 复测定 } \\
\text { 系数 } R^{2}\end{array}$ & $F$ 显著性 \\
检验
\end{tabular}

利用 $90 \%$ 保证率下枯季各月湖泊调蓄水量结果及公式(9)、(12) 可得到调节后的湖口枯季各月径流总 量及平均径流量 (图 9), 这意味着控制枯季各月湖口出流总量或平均流量不超过图 9 中的流量值即可满足 环湖灌区的水资源需求. 因此, 湖口站枯季 9 月至翌年 2 月的月均流量上限分别为 $2030.14 、 1129.62$ 、 
1069.54、1058.3、912.83 和 $1147.69 \mathrm{~m}^{3} / \mathrm{s}$.

湖口出流受到“五河”来水和长江来水的双重影 响, 要得到灌区水量供需平衡时长江干流流量, 需假 定“五河” 来水增加 $20 \%$ 、增加 $10 \%$ 、不变、减少 $10 \%$ 和减少 $20 \%$ 的 5 种不同情景, 根据调节后湖口枯季各 月径流总量及平均径流量 (图 9)、湖口枯季出流变化 规律(表 3 ) 及公式(11) 可模拟得到 5 种情景下的汉 口站枯季各月月均径流调节分析结果 (表 4). 各情景 中, 将模拟所得结果与汉口站实测 2003-2019 年枯 季各月平均流量相比, 排除模型无解和流量值为负的 情况, 只有情景 4 下的 9 月和情景 5下的 9-10 月存 在合理的汉口流量调节结果, 这表明枯季 9 月至翌年

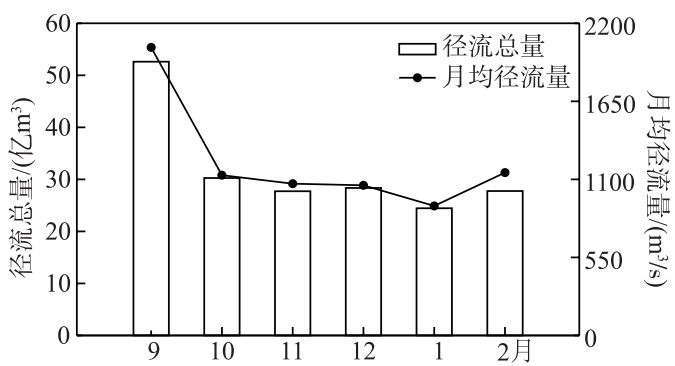

图 9 调节后鄱阳湖湖口站枯季径流量 Fig.9 Dry season runoff at Hukou Station of Lake Poyang after regulation

2月中, 只有 9-10月可通过三峡及其上游控制性水库群调节长江干流流量抑制湖口出流以满足环湖灌区 水资源需求, 11 月至翌年 2 月无论在何种情景下均无法通过调节长江干流流量使湖盆蓄存足够的水量. 关 于这一点, 许继军等 ${ }^{[11]}$ 研究认为三峡工程汛末蓄水期 10-11 月减泄流量对鄱阳湖的影响最大, 其他时期影 响较小; 丁惠君等 ${ }^{[14]}$ 认为三峡工程运行对环湖灌溉影响期主要为 10 月份; 吴培军等 ${ }^{[15]}$ 认为三峡及长江上 游干支流水库群 9-11 月蓄水加剧了鄱阳湖枯季缺水状况, 而 1-3 月补水作用较小; 要威等 ${ }^{[45]}$ 认为通过改 变长江上游水库群调度运行方式无法缓解鄱阳湖枯水情势. 上述研究均表明通过人工调节长江干流流量只 能在汛末蓄水期对鄱阳湖起到一定作用, 其他时期基本没有影响, 与本研究结果相似, 不同之处在于本研究 通过计算量化了调节长江干流流量的可行性. 此外, 本研究得到的可调节时段为 9-10月, 这可能是因为计 人了“五河” 来水变化对湖口出流变化的影响, 且三峡水库汛末蓄水时间也发生了变化 (之前为 $10-11$ 月).

然而, 即使在汛末蓄水期, 若通过三峡及其上游控制性水库群调节长江干流流量以满足环湖灌区缺水, 要 考虑其对于整个长江中下游及长江河口的影响; 若考虑鄱阳湖流域上游水库调度运行方案, 以 9 月为例, 仅从 水资源量角度来看, 鄱阳湖流域主要 7 座大型水库 (江口水库、万安水库、峡江水库、廖坊水库、洪门水库、大坳 水库、柘林水库) 的总增泄水量 ${ }^{[46]}$ 可达 42.55 亿 $\mathrm{m}^{3}$, 已经超过了 9 月湖泊调蓄水量, 无需再调节长江干流流量. 然而, 如此大的 “五河”增泄水量势, 必导致湖口出流加快, 实际上增泄的水量无法全部蓄存于湖盆中, 这将削弱 鄱阳湖流域上游水库的水量调节作用, 况且该举措会对水库的正常运用产生不利影响. 因此, 要从根本上解决 环湖灌区枯季缺水问题, 需在合理规划相协调的长江及鄱阳湖流域上游水库联合调度运行方案的基础上进行 进一步论证. 目前, 由众多学者提出的建设鄱阳湖水利枢纽工程能在枯季显著抬高湖泊水位 ${ }^{[47]}$, 虽然或许会引 起一些生态环境方面的不利影响 ${ }^{[17]}$, 但仍不失为行之有效的解决措施.

表 45 种不同情景下汉口站径流调节分析结果 *

Tab.4 Analysis on runoff regulation at Hankou Station under five different scenarios

\begin{tabular}{|c|c|c|c|c|c|c|}
\hline 时间 & 实测 & 情景 1 & 情景 2 & 情景 3 & 情景 4 & 情景 5 \\
\hline 9 月 & 28653.22 & 无解 & 无解 & 无解 & 24763.90 & 31018.89 \\
\hline 10 月 & 20280.47 & 无解 & 无解 & 无解 & 无解 & 17044.30 \\
\hline 11 月 & 15984.85 & 负值 & 负值 & 负值 & 负值 & 负值 \\
\hline 12 月 & 11407.52 & 负值 & 负值 & 负值 & 负值 & 负值 \\
\hline 1 月 & 11135.24 & 负值 & 负值 & 负值 & 负值 & 负值 \\
\hline 2 月 & 11026.47 & 负值 & 负值 & 负值 & 负值 & 负值 \\
\hline
\end{tabular}

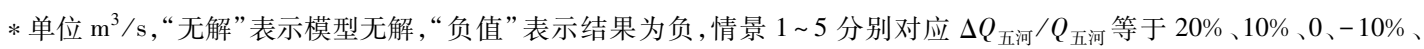
$-20 \%$.

本研究基于一些假定和简化条件,存在一定的不确定性,主要包括以下几点: (1) 鉴于三峡工程于 2003 年蓄水运行, 相对于整个 1953-2018 年实测水文数据系列较晚, 故本文水位保证率分析结果可能受到气候 
周期性变化的影响 ${ }^{[48]}$; (2) 在分析鄱阳湖流域枯季出人湖径流变化特征时, 对湖区未控区间径流采用面积 比拟法处理, 该方法假定流域降雨均匀分布; (3) 在分析通过调节长江干流流量给环湖灌区补水的可行性 时, 由于枯季人湖径流呈增加趋势, 按最不利原则考虑, 忽略了该部分, 认为湖泊水位容积变化全部由出湖 径流引起, 且未考虑湖床冲淤和人工采砂导致的湖盆形态变化的影响. 在今后的研究中, 应进一步考虑这些 影响, 以期为鄱阳湖区水资源优化调度、水资源管理等提供参考.

\section{4 结论}

近年来, 鄱阳湖枯水位下降导致了一系列生态环境和民生问题, 本文在诸多问题中选择环湖灌溉缺水 进行分析, 重新评估环湖灌区枯季缺水状况, 并初步探讨其应对方案, 主要得到如下结论:

1) 自 2003 年以来, 鄱阳湖枯季 9 月至翌年 2 月湖区水位发生不同程度下降, 尤以 9-11 月最为显著, $90 \%$ 保证率下水位降幅分别为 5.2\%、7.0\%、5.4\%.

2) 采用代表水文年法估算 $90 \%$ 保证率下鄱阳湖环湖灌区枯季 9 月至翌年 2 月的缺水量分别为 2.26 亿、 2.12 亿、0.57 亿、0.58 亿、0.55 亿、0.25 亿 $\mathrm{m}^{3}$.

3 ) 环湖灌区水资源供需临界平衡时, 湖口枯季 9 月至翌年 2 月月均流量分别为 $2030.14 、 1129.62$ 、 $1069.54 、 1058.3 、 912.83 、 1147.69 \mathrm{~m}^{3} / \mathrm{s}$.

4) 讨论长江中上游水利工程优化调度等方案, 发现只有 9-10 月可通过调节长江干流流量满足灌区用 水需求, 且必须是在 “五河” 来水减少的情况下. 受限于这些条件, 调节长江来水并非治本之策, 目前仍需采 取其他更为有效的手段以恢复鄱阳湖的水位及其过程.

致谢: 感谢胡浩博士在论文修改方面提供的帮助.

\section{5 附录}

附表 I ～III 见电子版( DOI: 10.18307/2022.0220).

\section{6 参考文献}

[ 1 ] Hu CH, Ruan BQ, Zhang SH eds. The evolution and regulation of the relationship between the Yangtze River and Dongting Lake and Lake Poyang. Beijing: Science Press, 2017. [胡春宏, 阮本清, 张双虎. 长江与洞庭湖鄱阳湖关系演变及其 调控. 北京: 科学出版社, 2017.]

[ 2 ] Zhao GJ, Hörmann G, Fohrer N et al. Streamflow trends and climate variability impacts in Lake Poyang Basin, China. Water Resources Management, 2010, 24(4) : 689-706. DOI: 10.1007/s11269-009-9465-7.

[ 3 ] Guo H, Hu Q, Jiang T. Annual and seasonal streamflow responses to climate and land-cover changes in the Lake Poyang basin, China. Journal of Hydrology, 2008, 355(1/2/3/4) : 106-122. DOI : 10.1016/j.jhydrol.2008.03.020.

[ 4 ] Shi SY, Cheng HQ, Zheng SW et al. Erosional topography of the tidal limit in the Yangtze River in flood seasons after the river closure at Three Gorges. Haiyang Xuebao, 2017, 39(3) : 85-95. [石盛玉, 程和琴, 郑树伟等. 三峡截流以来长 江洪季潮区界变动河段冲刷地貌. 海洋学报, 2017, 39(3): 85-95.]

[ 5 ] Zheng SW. Adaptive behavior of channel morphodynamics and micro-geomophology evolution under human activities from Hankou to Wusongkou reach of the Yangtze River[Dissertation]. Shanghai: East China Normal University, 2018. [郑树 伟. 长江汉口至吴淞口河槽冲淤与微地貌演变对人类活动的自适应行为研究 [学位论文]. 上海: 华东师范大 学, 2018.]

[ 6 ] Fang CM, Cao WH, Mao JX et al. Relationship between Lake Poyang and Yangtze River and influence of Three Georges Reservoir. Journal of Hydraulic Engineering, 2012, 43(2) : 175-181. [方春明, 曹文洪, 毛继新等. 鄱阳湖与长江关 系及三峡蓄水的影响. 水利学报, 2012, 43(2) : 175-181.]

[ 7 ] Ye XC, Li YL, Li XH et al. Factors influencing water level changes in China's largest freshwater lake, Lake Poyang, in the past 50 years. Water International, 2014, 39(7) : 983-999. DOI: 10.1080/02508060.2015.986617.

[ 8 ] Liu TH, An ZW, Chai ZH et al. Changes of water and sediment flux and typical sectional shape of five rivers flowing into the Lake Poyang. Journal of Yangtze River Scientific Research Institute, 2020, 37(11): 8-13,39. [刘同宦, 安智伟, 柴朝 晖等. 鄱阳湖“五河” 人湖水沙通量及典型断面形态变化特性分析. 长江科学院院报, 2020, 37(11): 8-13,39.] 
[ 9 ] Zhao JK, Li LX, Li JF et al. The analysis on the response of the water level change trend to human activities in Lake Poyang. Journal of Jiangxi Normal University: Natural Science Edition, 2019, 43(5): 532-544. [ 赵军凯, 李立现, 李九发 等. 鄱阳湖水位变化趋势性对人类活动响应分析. 江西师范大学学报: 自然科学版, 2019, 43(5): 532-544.]

[10] Dai X, Wan RR, Yang GS. Non-stationary water-level fluctuation in China's Lake Poyang and its interactions with Yangtze River. Journal of Geographical Sciences, 2015, 25(3) : 274-288. DOI: 10.1007/s11442-015-1167-x.

[11] Xu JJ, Chen J. Study on the impact of Three Gorges reservoir on Lake Poyang and some proposals. Journal of Hydraulic Engineering, 2013, 44(7) : 757-763. [许继军, 陈进. 三峡水库运行对鄱阳湖影响及对策研究. 水利学报, 2013, 44(7): 757-763.]

[12] Jiang F, Qi SH, Liao FQ et al. Hydrological and sediment effects from sand mining in Lake Poyang during 2001-2010. Acta Geographica Sinica, 2015, 70(5): 837-845. DOI: 10.11821/dlxb201505014. [江丰，齐述华，廖富强等. 20012010 年鄱阳湖采砂规模及其水文泥沙效应. 地理学报, 2015, 70(5): 837-845.]

[13] Xu B, Chen GC, Chen L. Analysis on the Evolution characteristics of precipitation in Lake Poyang Basin under changing environment. Express Water Resources \& Hydropower Information, 2017, 38(12)：36-38. [许斌,陈广才, 陈丽. 变化环 境下鄱阳湖流域降水演变特征分析. 水利水电快报, 2017, 38(12): 36-38.]

[14] Ding HJ, Luan ZY, Xu XF. Impact of the Three Gorges project on the Lake Poyang water use. Resources and Environment in the Yangtze Basin, 2014, 23(12) : 1671-1677. DOI: 10.11870/cjlyzyyhj201412005. [丁惠君, 奕震宇, 许新发. 三 峡工程运用对鄱阳湖水资源利用影响分析. 长江流域资源与环境, 2014, 23(12)：1671-1677.]

[15] Wu PJ, Wan XM, Xu JM et al. Changes of water levels in low-water season in Lake Poyang and it's countermeasures. Water Resources Protection, 2019, 35(6) : 104-108,123. [吴培军, 万晓明, 徐继铭等. 鄱阳湖枯水期水位变化及应对措 施. 水资源保护, 2019, 35(6) : 104-108,123.]

[16] Zhang Q, Li L, Wang YG et al. Has the Three-Gorges Dam made the Lake Poyang wetlands wetter and drier? Geophysical Research Letters, 2012, 39(20) : L20402. DOI: 10.1029/2012GL053431.

[17] Zhou JJ, Zhang M. Eco-problem of Lake Poyang in Yangtze River and effect of sluice gate construction at lake's outlet. Water Resources Protection, 2019, 35(2) : 1-12. [ 周建军, 张曼. 长江鄱阳湖问题的原因及湖口建闸的影响. 水资源保 护, 2019, 35(2): 1-12.]

[18] Su XL, Song Y, Liu JM et al. Spatiotemporal optimize allocation of water resources coupling groundwater simulation model in canal-well irrigation district. Transactions of the Chinese Society of Agricultural Engineering, 2016, 32(13) : 43-51. [粟 晓玲, 宋悦, 刘俊民等. 耦合地下水模拟的渠井灌区水资源时空优化配置. 农业工程学报, 2016, 32(13): 43-51.]

[19] Chen HG, Wang QY, Li XN et al. Optimal water resources planning based on interval-parameter two-stage robust stochastic programming model. Transactions of the Chinese Society for Agricultural Machinery, 2019, 50(3) : 271-280. [ 陈红光, 王琼雅，李晓宁等. 基于区间两阶段鲁棒优化模型的灌区水资源优化配置. 农业机械学报, 2019, 50(3): 271-280.]

[20] Wan XQ, Xu XF. Analysis of supply and demand balance of water resources around Lake Poyang. Yangtze River, 2010,41 (6)：43-47.[万小庆，许新发. 鄱阳湖环湖区水资源供需平衡分析. 人民长江，2010，41(6)：43-47.]

[21] Dai SL. Optimal dispatching of joint water resources in shanhu-hewangba reservoir irrigation area of Liuhe District[Dissertation]. Yangzhou: Yangzhou University, 2020. [戴士岗. 六合区山湖-河王坝水库灌区水资源联合优化调配研究 [学 位论文]. 扬州: 扬州大学, 2020.]

[22] Ma YL, Qie HM, Peng XM et al. The reserve distribution characteristics of organic carbon in soil from Lake Poyang and the surrounding economic region. Rock and Mineral Analysis, 2014, 33(2): 246-255. [马逸麟, 郄海满, 彭晓玫等. 江 西省鄱阳湖及周边经济区土壤有机碳储量分布特征. 岩矿测试, 2014, 33(2) : 246-255.]

[23] Huang HJ, Liu XD. Analysis of influence of low water level of Lake Poyang on around-lake agricultural irrigation. Yangtze River, 2015, 46(11) : 15-17,35. [黄华金, 刘小东. 鄱阳湖低水位对环湖区农业灌溉的影响分析. 人民长江, $2015, \mathbf{4 6}(11): 15-17,35$.

[24] Li GW, Yu ZW, Chen JL. Study on the relationship between dynamic level-area and level-volume of Lake Poyang. Jiangxi Hydraulic Science \& Technology, 2015, 41(1): 21-26,34. [李国文, 喻中文, 陈家霖. 鄱阳湖动态水位 面积、水位 容积关系研究. 江西水利科技, 2015, 41(1): 21-26,34.]

[25] Guo H, Hu Q, Zhang Q et al. Effects of the Three Gorges dam on Yangtze River flow and river interaction with Lake Poyang, China: 2003-2008. Journal of Hydrology, 2012, 416/417: 19-27. DOI: 10.1016/j.jhydrol.2011.11.027. 
[26] Min Q, Zhan LS. Characteristics of low-water level changes in Lake Poyang during 1952-2011. J Lake Sci, 2012, 24 ( 5) : 675-678. DOI: 10.18307/2012.0505. [闵骞, 占腊生. 1952-2011 年鄱阳湖枯水变化分析. 湖泊科学, 2012, 24(5): 675-678.]

[27] Sun P, Zhang Q, Chen XH. Changing properties of low streamflow, possible causes and implications. Geographical Research, 2011, 30 (9) : 1702-1712. [孙鹏, 张强, 陈晓宏. 鄱阳湖流域枯水径流演变特征、成因与影响. 地理研究, 2011, 30(9) : 1702-1712.]

[28] Zhan DJ, Xu XY, Chen YF eds. Engineering hydrology. Beijing: China Water \& Power Press, 2010. [詹道江, 徐向阳, 陈元芳. 工程水文学. 北京: 中国水利水电出版社, 2010.]

[29] Zou DS, Chen L, Liu XD. Quantifying the guarantee rate variation of irrigation water intake in the Lake Poyang area. China Rural Water and Hydropower, 2018, (8): 67-71,76. [邹大胜, 陈龙, 刘小东. 鄱阳湖区灌溉取水保证率变化的定 量评估. 中国农村水利水电, 2018, (8): 67-71,76.]

[30] Wu PJ, Duan M, Chen J et al. Influence of Lake Poyang Water Control Project dispatching on water resources utilization in Lake Poyang. Yangtze River, 2020, 51(9): 101-106. [ 吴培军, 段明, 陈江等. 鄱阳湖水利枢纽调度对鄱阳湖水资源 利用的影响. 人民长江, $2020,51(9):$ 101-106.]

[31] Xu WH, Zhang SH, Jiang YZ et al. Analysis of water resources security issue of Lake Poyang. Journal of China Institute of Water Resources and Hydropower Research, 2011, 9(4): 274-278. [ 徐卫红, 张双虎, 蒋云钟等. 鄱阳湖区水资源安全 问题分析. 中国水利水电科学研究院学报, 2011, 9(4): 274-278.]

[32] Hamed KH. Trend detection in hydrologic data: The Mann-Kendall trend test under the scaling hypothesis. Journal of Hydrology, 2008, 349(3/4) : 350-363. DOI: 10.1016/j.jhydrol.2007.11.009.

[33] Cheng HQ, Chen JY, Chen ZJ et al. Mapping sea level rise behavior in an estuarine delta system: A case study along the Shanghai Coast. Engineering, 2018, 4(1) : 156-163. DOI: 10.1016/j.eng.2018.02.002.

[34] Shi SY, Cheng HQ, Xuan XN et al. Fluctuations in the tidal limit of the Yangtze River estuary in the last decade. Science China: Earth Sciences, 2018, 48(8): 1085-1095. DOI: 10.1360/N072017-00130. [石盛玉, 程和琴, 玄晓娜等. 近十 年来长江河口潮区界变动. 中国科学: 地球科学, 2018, 48(8): 1085-1095.]

[35] Liu JY, Zhang Q, Deng XY et al. Quantitative analysis the influences of climate change and human activities on hydrological processes in Poyang Basin. J Lake Sci, 2016, 28(2) : 432-443. DOI: 10.18307/2016.0224. [刘剑宇, 张强, 邓晓宇 等. 气候变化和人类活动对鄱阳湖流域径流过程影响的定量分析. 湖泊科学, 2016, 28(2): 432-443.]

[36] Wang D, Zhang SH, Wang GL et al. Quantitative assessment of water stage changes of Lake Poyang in dry period and its influencing factors. Journal of Hydroelectric Engineering, 2020, 39(3): 1-10. [王丹, 张双虎, 王国利等. 鄱阳湖枯水 期水位变化及其影响因素量化分析. 水力发电学报, 2020, 39(3): 1-10.]

[37] You ZQ, Yuan D, Li CW. Influence of controlled reservoirs operation in five tributaries of Lake Poyang on hydrological regime in dry season. Yangtze River, 2021, 52(3): 53-57. [游中琼, 袁迪, 李昌文. “五河” 控制性水库对鄱阳湖枯水 期水文情势的影响. 人民长江, 2021, 52(3): 53-57.]

[38 ] Ministry of Housing and Urban-Rural Construction of the People's Republic of China. Design standard for irrigation and drainage engineering (GB 50288-2018). Beijing, 2018. [中华人民共和国住房和城乡建设部. 灌溉与排水工程设计 标准( GB 50288-2018). 北京, 2018.]

[39] Xu GH, Qin ZW. Flood estimation methods for Lake Poyang area. J Lake Sci, 1998, 10(1) : 31-36. DOI: 10.18307/ 1998.0105. [徐高洪, 秦智伟. 鄱阳湖区间洪水计算方法. 湖泊科学, 1998, 10(1): 31-36.]

[40] Huang Y, Xu GH, Shen YZ et al. Research on analysis method of water resources quantity balance in plain river-net areas. Yangtze River, 2008, 39(17) : 24-26,45,115. [黄燕, 徐高洪, 沈燕舟等. 平原水网区水资源量平衡分析方法研究. 人民长江, $2008,39(17): 24-26,45,115$. ]

[41] Guo H, Su BD, Wang YJ et al. Runoff coefficients change and the analysis of the relationship between climate factors and runoff coefficients in Lake Poyang Basin (China) : 1955-2002. J Lake Sci, 2007, 19(2): 163-169. DOI: 10.18307/ 2007.0209. [ 郭华, 苏布达, 王艳君等. 鄱阳湖流域 1955-2002 年径流系数变化趋势及其与气候因子的关系. 湖泊 科学, $2007,19(2): 163-169$. $]$

[42] Bing JP, Deng PX, Lv SY et al. The analysis of water exchange regime research on Lake Poyang and Yangtze River and driving factors. Scientia Sinica: Technologica, 2017, 47(8): 856-870. DOI: 10.1360/N092016-00347. [邴建平, 邓鹏 金金, 吕孙云等. 鄱阳湖与长江干流水量交换效应及驱动因素分析. 中国科学: 技术科学, 2017, 47(8): 856-870.] 
[43] Hu Q, Feng S, Guo H et al. Interactions of the Yangtze River flow and hydrologic processes of the Lake Poyang, China. Journal of Hydrology, 2007, 347(1/2) : 90-100. DOI: 10.1016/j.jhydrol.2007.09.005.

[44] Hu ZP, Fu J. Quantitative study on hydrology relationship between the Yangtze River and Lake Poyang and its changes. Journal of Hydraulic Engineering, 2018, 49 (5) : 570-579. [胡振鹏, 傅静. 长江与鄱阳湖水文关系及其演变的定量分 析. 水利学报, 2018, 49(5): 570-579.]

[45] Yao W, Yu QH, You ZQ. Study on reservoirs operation at upper Yangtze River for alleviating low water situation of Lake Poyang. Yangtze River, 2015, 46(24) : 1-5,20. [要威, 余启辉, 游中琼. 长江上游水库调度缓解鄱阳湖枯水情势作 用研究. 人民长江, 2015, 46(24): 1-5,20.]

[46] Wu SC, Chang HJ, Xiao CH. Study on emergent water supply solutions for Lake Poyang region and estuary area of 5-rivers into Lake Poyang. Yangtze River, 2016, 47(21): 35-38,71. [ 吴三潮, 常汉军, 肖昌虎. 鄱阳湖区及五河地区水量应 急调度方案研究. 人民长江, 2016, 47(21): 35-38,71.]

[47] Wang P, Lai GY, Huang XL. Simulation of the impact of Lake Poyang Project on the dynamic of lake water level. J Lake $S c i, 2014,26$ (1) : 29-36. DOI: 10.18307/2014.0104. [王鹏, 赖格英, 黄小兰. 鄱阳湖水利枢纽工程对湖泊水位变 化影响的模拟. 湖泊科学, 2014, 26(1) : 29-36.]

[48] Peng W. Study on the hydrological characteristics of dry season in Lake Poyang and it's drought-limited water level[ Dissertation]. Wuhan: Changjiang River Scientific Research Institute, 2015. [ 彭薇. 鄱阳湖枯水期水文特征分析及旱限水位 研究 [学位论文]. 武汉:长江科学院, 2015.] 
附表 I 各拟合线型的概率密度函数或概率分布函数

Attached Tab. I The distribution (or density) function of each probability distribution

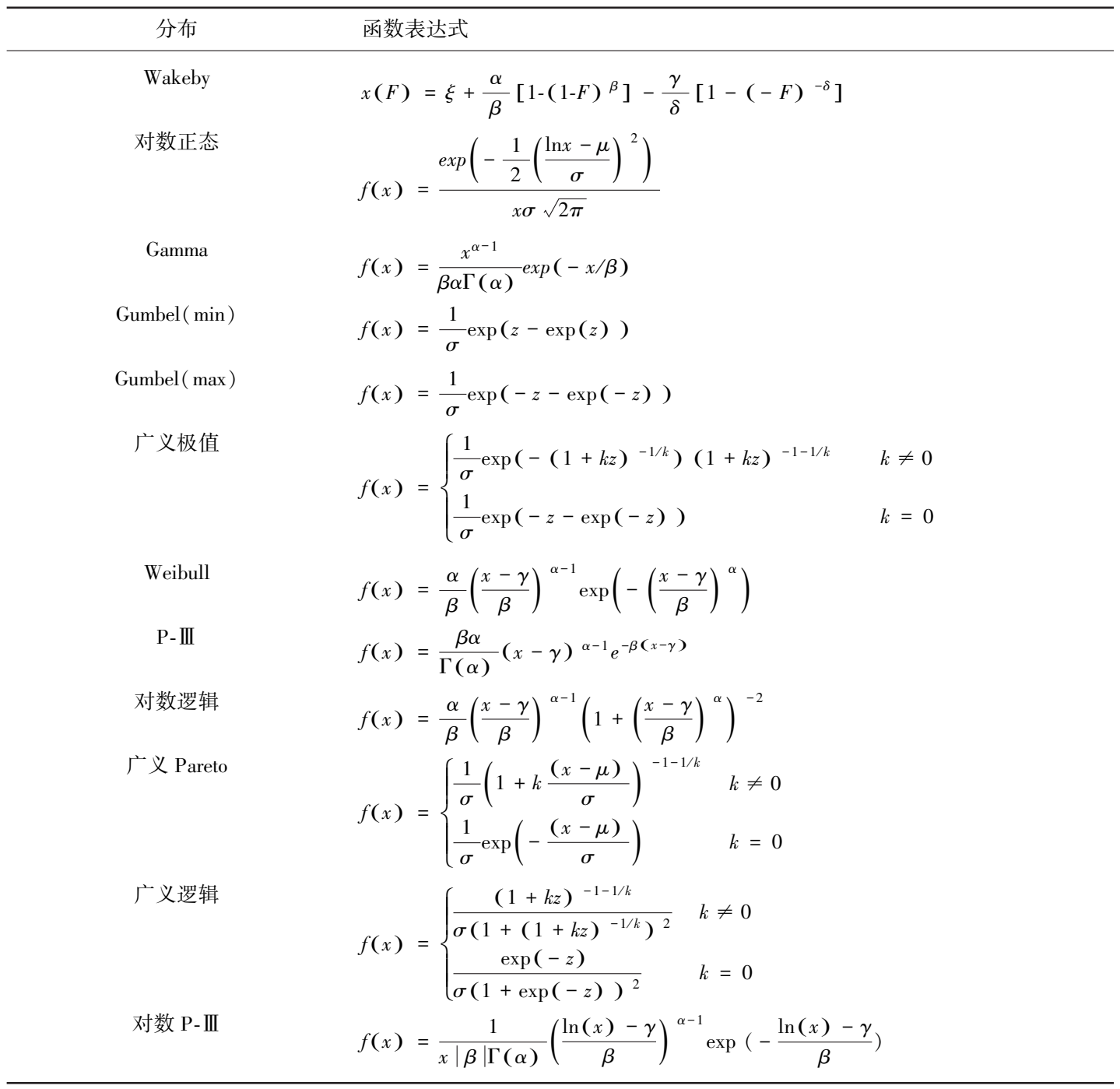


附表 II 1953-2002 系列各概率分布拟合的参数估计结果

Attached Tab. II Parameter estimation results for each probability distribution fitted to the 1953-2002 series

\begin{tabular}{|c|c|c|c|c|c|c|c|}
\hline 分布 & 年均 & 9月 & 10 月 & 11 月 & 12 月 & 1 月 & 2 月 \\
\hline \multirow[t]{5}{*}{ Wakeby } & $a=6.25$ & $a=20.25$ & $a=24.54$ & $a=12.75$ & $a=67.65$ & $a=3.02$ & $a=4.83$ \\
\hline & $b=4.27$ & $b=5.13$ & $b=9.93$ & $b=8.69$ & $b=39.44$ & $b=1.33$ & $b=3.68$ \\
\hline & $g=0.52$ & $g=1.26$ & $g=2.99$ & $g=2.74$ & $g=2.27$ & $g=0.17$ & $g=1.70$ \\
\hline & $d=0.13$ & $d=0$ & $d=-0.51$ & $d=-0.46$ & $d=-0.39$ & $d=0.52$ & $d=-0.41$ \\
\hline & $x=11.61$ & $x=11.46$ & $x=10.36$ & $x=9.00$ & $x=6.47$ & $x=7.29$ & $x=7.38$ \\
\hline \multirow[t]{2}{*}{ 对数正态 } & $s=0.07$ & $s=0.12$ & $s=0.12$ & $s=0.13$ & $s=0.13$ & $s=0.12$ & $s=0.12$ \\
\hline & $m=2.59$ & $m=2.77$ & $m=2.67$ & $m=2.49$ & $m=2.27$ & $m=2.18$ & $m=2.26$ \\
\hline \multirow[t]{2}{*}{ Gamma } & $a=217.02$ & $a=68.73$ & $a=71.72$ & $a=62.29$ & $a=59.13$ & $a=57.67$ & $a=63.99$ \\
\hline & $b=0.06$ & $b=0.23$ & $b=0.20$ & $b=0.20$ & $b=0.17$ & $b=0.16$ & $b=0.15$ \\
\hline \multirow[t]{2}{*}{ Gumbel ( min) } & $s=0.71$ & $s=1.51$ & $s=1.34$ & $s=1.20$ & $s=0.99$ & $s=0.92$ & $s=0.94$ \\
\hline & $m=13.80$ & $m=16.88$ & $m=15.36$ & $m=12.89$ & $m=10.35$ & $m=9.48$ & $m=10.16$ \\
\hline \multirow[t]{2}{*}{ Gumbel(max) } & $s=0.71$ & $s=1.51$ & $s=1.34$ & $s=1.20$ & $s=0.99$ & $s=0.92$ & $s=0.94$ \\
\hline & $m=12.98$ & $m=15.14$ & $m=13.81$ & $m=11.50$ & $m=9.20$ & $m=8.42$ & $m=9.08$ \\
\hline \multirow[t]{3}{*}{ 广义极值 } & $k=-0.15$ & $k=-0.33$ & $k=-0.32$ & $k=-0.21$ & $k=-0.08$ & $k=0.03$ & $k=-0.25$ \\
\hline & $s=0.82$ & $s=1.96$ & $s=1.76$ & $s=1.50$ & $s=1.12$ & $s=0.89$ & $s=1.18$ \\
\hline & $m=13.02$ & $m=15.38$ & $m=14.01$ & $m=11.58$ & $m=9.21$ & $m=8.41$ & $m=9.17$ \\
\hline \multirow[t]{2}{*}{ Weibull } & $a=18.09$ & $a=9.69$ & $a=9.83$ & $a=9.43$ & $a=9.14$ & $a=10.03$ & $a=9.84$ \\
\hline & $b=13.72$ & $b=16.74$ & $b=15.23$ & $b=12.75$ & $b=10.24$ & $b=9.30$ & $b=10.03$ \\
\hline \multirow[t]{3}{*}{ P- III } & $a=90.70$ & $a=30.86$ & $a=30.86$ & $a=26.30$ & $a=26.30$ & $a=26.30$ & $a=26.30$ \\
\hline & $b=10.16$ & $b=2.89$ & $b=3.18$ & $b=3.24$ & $b=4.04$ & $b=4.41$ & $b=4.10$ \\
\hline & $g=4.46$ & $g=5.34$ & $g=4.86$ & $g=4.06$ & $g=3.26$ & $g=2.98$ & $g=3.21$ \\
\hline \multirow[t]{2}{*}{ 对数逻辑 } & $a=26.16$ & $a=13.60$ & $a=13.70$ & $a=13.39$ & $a=13.25$ & $a=14.72$ & $a=13.81$ \\
\hline & $b=13.31$ & $b=15.82$ & $b=14.41$ & $b=12.03$ & $b=9.64$ & $b=8.81$ & $b=9.48$ \\
\hline \multirow[t]{3}{*}{ 广义 Pareto } & $k=-0.71$ & $k=-1.11$ & $k=-1.09$ & $k=-0.83$ & $k=-0.57$ & $k=-0.36$ & $k=-0.92$ \\
\hline & $s=2.35$ & $s=7.12$ & $s=6.29$ & $s=4.60$ & $s=2.93$ & $s=2.04$ & $s=3.82$ \\
\hline & $m=12.02$ & $m=12.63$ & $m=11.57$ & $m=9.68$ & $m=7.91$ & $m=7.45$ & $m=7.62$ \\
\hline \multirow[t]{3}{*}{ 广义逻辑 } & $k=0.08$ & $k=-0.03$ & $k=-0.02$ & $k=0.04$ & $k=0.12$ & $k=0.19$ & $k=0.02$ \\
\hline & $s=0.50$ & $s=1.09$ & $s=0.97$ & $s=0.89$ & $s=0.71$ & $s=0.60$ & $s=0.68$ \\
\hline & $m=13.33$ & $m=16.06$ & $m=14.62$ & $m=12.13$ & $m=9.63$ & $m=8.76$ & $m=9.59$ \\
\hline \multirow[t]{3}{*}{ 对数 P-III } & $a=31.47$ & $a=23.17$ & $a=11.34$ & $a=705.37$ & $a=73.45$ & $a=5.48$ & $a=20690.00$ \\
\hline & $b=0.01$ & $b=-0.03$ & $b=-0.04$ & $b=0$ & $b=0.01$ & $b=0.05$ & $b=0$ \\
\hline & $g=2.22$ & $g=3.36$ & $g=3.08$ & $g=5.87$ & $g=1.17$ & $g=1.89$ & $g=20.21$ \\
\hline
\end{tabular}


附表 III 1953-2018 系列各概率分布拟合的参数估计结果

Attached Tab. III Parameter estimation results for each probability distribution fitted to the 1953-2018 series

\begin{tabular}{|c|c|c|c|c|c|c|c|}
\hline 分布 & 年均 & 9 月 & 10 月 & 11 月 & 12 月 & 1 月 & 2 月 \\
\hline \multirow[t]{5}{*}{ Wakeby } & $a=6.44$ & $a=18.73$ & $a=41.31$ & $a=15.98$ & $a=22.89$ & $a=2.34$ & $a=6.15$ \\
\hline & $b=3.41$ & $b=3.77$ & $b=11.34$ & $b=8.03$ & $b=18.47$ & $b=0.94$ & $b=10.75$ \\
\hline & $g=0.41$ & $g=0.74$ & $g=3.20$ & $g=2.59$ & $g=1.89$ & $g=0.21$ & $g=2.85$ \\
\hline & $d=0.18$ & $d=0.16$ & $d=-0.49$ & $d=-0.40$ & $d=-0.26$ & $d=0.42$ & $d=-0.63$ \\
\hline & $x=11.24$ & $x=10.85$ & $x=8.54$ & $x=8.21$ & $x=6.99$ & $x=7.36$ & $x=7.20$ \\
\hline \multirow[t]{2}{*}{ 对数正态 } & $s=0.07$ & $s=0.14$ & $s=0.15$ & $s=0.14$ & $s=0.13$ & $s=0.12$ & $s=0.13$ \\
\hline & $m=2.58$ & $m=2.74$ & $m=2.63$ & $m=2.46$ & $m=2.26$ & $m=2.18$ & $m=2.24$ \\
\hline \multirow[t]{2}{*}{ Gamma } & $a=185.30$ & $a=57.57$ & $a=50.98$ & $a=51.27$ & $a=57.41$ & $a=57.46$ & $a=58.53$ \\
\hline & $b=0.07$ & $b=0.27$ & $b=0.28$ & $b=0.23$ & $b=0.17$ & $b=0.16$ & $b=0.16$ \\
\hline \multirow[t]{2}{*}{ Gumbel( $\min$ ) } & $s=0.76$ & $s=1.61$ & $s=1.53$ & $s=1.29$ & $s=0.99$ & $s=0.92$ & $s=0.96$ \\
\hline & $m=13.63$ & $m=16.58$ & $m=14.92$ & $m=12.57$ & $m=10.23$ & $m=9.45$ & $m=10.03$ \\
\hline \multirow[t]{2}{*}{ Gumbel( max) } & $s=0.76$ & $s=1.61$ & $s=1.53$ & $s=1.29$ & $s=0.99$ & $s=0.92$ & $s=0.96$ \\
\hline & $m=12.76$ & $m=14.73$ & $m=13.15$ & $m=11.08$ & $m=9.08$ & $m=8.39$ & $m=8.92$ \\
\hline \multirow[t]{3}{*}{ 广义极值 } & $k=-0.25$ & $k=-0.42$ & $k=-0.38$ & $k=-0.24$ & $k=-0.04$ & $k=0.06$ & $k=-0.19$ \\
\hline & $s=0.94$ & $s=2.17$ & $s=2.05$ & $s=1.63$ & $s=1.07$ & $s=0.87$ & $s=1.18$ \\
\hline & $m=12.84$ & $m=15.06$ & $m=13.43$ & $m=11.21$ & $m=9.08$ & $m=8.37$ & $m=8.98$ \\
\hline \multirow[t]{2}{*}{ Weibull } & $a=16.73$ & $a=8.83$ & $a=8.26$ & $a=8.56$ & $a=9.12$ & $a=9.65$ & $a=9.38$ \\
\hline & $b=13.56$ & $b=16.45$ & $b=14.79$ & $b=12.44$ & $b=10.13$ & $b=9.32$ & $b=9.92$ \\
\hline \multirow[t]{3}{*}{ P-III } & $a=90.70$ & $a=26.30$ & $a=22.68$ & $a=22.68$ & $a=26.30$ & $a=26.30$ & $a=26.30$ \\
\hline & $b=10.31$ & $b=2.52$ & $b=2.42$ & $b=2.88$ & $b=4.08$ & $b=4.42$ & $b=4.16$ \\
\hline & $g=4.40$ & $g=5.22$ & $g=4.68$ & $g=3.94$ & $g=3.22$ & $g=2.97$ & $g=3.16$ \\
\hline \multirow[t]{2}{*}{ 对数逻辑 } & $a=23.90$ & $a=12.29$ & $a=11.45$ & $a=12.12$ & $a=13.33$ & $a=14.31$ & $a=13.31$ \\
\hline & $b=13.12$ & $b=15.45$ & $b=13.84$ & $b=11.66$ & $b=9.54$ & $b=8.80$ & $b=9.35$ \\
\hline \multirow[t]{3}{*}{ 广义 Pareto } & $k=-0.92$ & $k=-1.31$ & $k=-1.21$ & $k=-0.90$ & $k=-0.50$ & $k=-0.32$ & $k=-0.80$ \\
\hline & $s=3.03$ & $s=8.86$ & $s=7.89$ & $s=5.23$ & $s=2.69$ & $s=1.95$ & $s=3.54$ \\
\hline & $m=11.61$ & $m=11.82$ & $m=10.47$ & $m=9.08$ & $m=7.87$ & $m=7.44$ & $m=7.50$ \\
\hline \multirow[t]{3}{*}{ 广义逻辑 } & $k=0.02$ & $k=-0.07$ & $k=-0.05$ & $k=0.02$ & $k=0.14$ & $k=0.21$ & $k=0.05$ \\
\hline & $s=0.54$ & $s=1.15$ & $s=1.11$ & $s=0.95$ & $s=0.69$ & $s=0.59$ & $s=0.70$ \\
\hline & $m=13.17$ & $m=15.79$ & $m=14.13$ & $m=11.79$ & $m=9.49$ & $m=8.71$ & $m=9.41$ \\
\hline \multirow[t]{3}{*}{ 对数 P-III } & $a=1151.4$ & $a=11.93$ & $a=8.42$ & $a=93.50$ & $a=32.24$ & $a=5.97$ & $a=871.08$ \\
\hline & $b=0$ & $b=-0.04$ & $b=-0.05$ & $b=-0.01$ & $b=0.02$ & $b=0.05$ & $b=0$ \\
\hline & $g=0.09$ & $g=3.21$ & $g=3.06$ & $g=3.83$ & $g=1.53$ & $g=1.88$ & $g=-1.59$ \\
\hline
\end{tabular}

